\title{
Comparative study between the NLPI controller and the CPI controller
}

\author{
Touhami Mohammed ${ }^{1}$, Pierre Sicard ${ }^{2}$, Hazzab Abdeljebar ${ }^{3}$, Fouad Mokhtari $^{4}$ \\ ${ }^{1,3}$ Department of Electrical Engineering, university Mohammed TAHRI Béchar, Algeria \\ 2,4 Department of Electrical Engineering and Computer Engineering, Université of Quebec at Trois-Rivières, Cannada
}

\begin{tabular}{l}
\hline \hline Article Info \\
\hline Article history: \\
Received Jan 6, 2019 \\
Revised Mar 21, 2019 \\
Accepted Apr 12, 2019 \\
\hline Keywords: \\
NLPI (Non-linear PI) \\
CPI (Classical PI) \\
IFOC (Indirect Vector Control) \\
MAS (Asynchronous Machine) \\
\end{tabular}

\begin{abstract}
Unquestionably, the classic CPI controller dominates the industry and has the advantage of being simple and easy to implement. Because its setting remains intuitive and more practical. On the other hand, these disadvantages lie in the fact that most of them reach a compromise in terms of speed of response and stability. Even worse, such an approach becomes insufficient at the increasingly demanding speeds demanded by the industry. In this context the NLPI controller is currently presented as an alternative. With its simple tuning method and robustness to process parameter variations, it stands out as a valuable addition to the toolbox of control engineering specialists. This paper aims to provide a simulation-based study using a MAS controlled by IFOC, comparing the PI controller system to the NLPI controller system. The results will be in favor of the last one.
\end{abstract}

Copyright (C) 2019 Institute of Advanced Engineering and Science. All rights reserved.

Corresponding Author:

Touhami Mohammed, Department of Electrical Engineering, University Mohammed TAHRI Béchar, B.P 417 City of Kenadsa Road - 08000 Béchar - Algeria. Email: tmoky13@gmail.com

\section{INTRODUCTION}

Currently, the NLPI controller currently presents itself as an alternative to both conventional CPI methods and modern model-based approaches to solving control problems subject to high variations and dynamics. The nonlinearities that occur at high speeds, means that the use of the CPI controller to control the speed of the asynchronous machine "MAS" is often characterized by an overrun in tracking mode and a bad rejection of load disturbance [1-3].

This is mainly due to the fact that controller gains cannot be granted to simultaneously resolve overflow and load disturbance rejection problems, as the overload removal setting will result in a bad charge rejection. The disruption of the load on the one hand and live on that on the other hand. However, the situation becomes more and more complicated for high speeds. It is from here that other types of control, otherwise technologically designed like the NLPI "non-linear PI", have to be used to manage par excellence and simultaneously the constraints relating to the overrun and to charge disturbance rejection [4-8].

The NLPI controller has therefore emerged as an alternative that combines easy applicability of conventional PI control methods with the power of modern model-based approaches. The NLPI controller foundation deals with real disturbances and modeling uncertainties together, so that only a very coarse process model is needed to design a control loop, making the NLPI controller an attractive choice for practitioners and promises good robustness against process variations. These current applications range from power electronics, motion control and superconducting radio frequency cavities to voltage and temperature control $[8,9]$. 


\section{CONTROL TECHNIQUES}

\subsection{CPI Controller}

Figure 1 illustrates the block diagram of MAS control by a CPI.

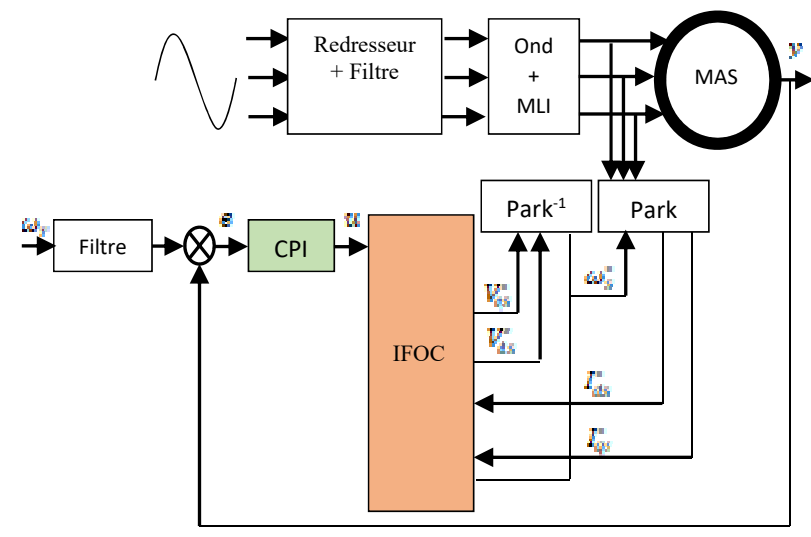

Figure 1. Control of MAS by CPI

Obviously, the CPI controller makes it possible to correct within a suitable time the difference that exists between a setpoint (speed, temperature, pressure, position) and its associated measurement return, by increasing or decreasing the output of the MAS and this, by the intermediate of two main parameters called gains (Proportional gain and Integral gain), which can accelerate, delay and stabilize this correction. The regulation function can be embodied in the form of a black box that can be represented by a comparator with 2 inputs (setpoint and return), the result of this comparator controls the output of the MAS [9, 11-15].

However, if the value of the feedback value is greater than the value of the setpoint, the difference is positive and the CPI controller will slow down the motor. Conversely, if the value of the measurement feedback is lower than the value of the setpoint, the difference is negative and the CPI controller will make sure to accelerate the motor. The response time of the system is adjustable via two gain parameters. In our case, the cruise control is used to determine the reference torque, in order to maintain the corresponding speed. The velocity dynamics is given by the following mechanical equation:

$$
F(s)=\frac{\omega}{C_{e m}}=\frac{P}{f_{c}+J . s}
$$

For this purpose, the simplified block diagram of the control system based on a controller CPI is given in Figure 2.

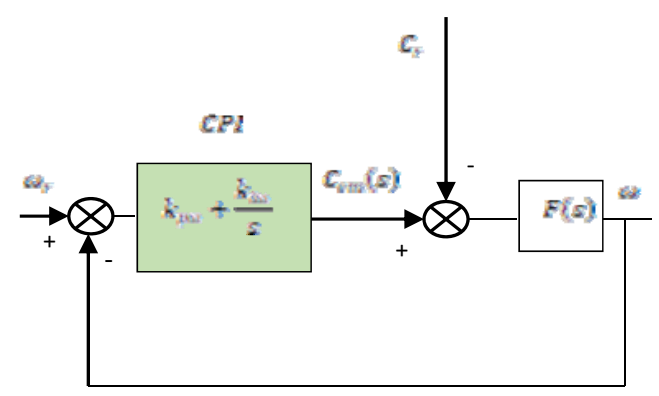

Figure 2. Block diagram of speed control by a CPI

Then, the closed loop transfer function is written as follows:

$\frac{\omega}{\omega_{r}}=\frac{\left(k_{p \omega} \cdot s+k_{i \omega}\right) \frac{P}{J}}{\rho(s)}$

Comparative study between the NLPI controller and the CPI controller (Touhami Mohammed) 
The characteristic equation $\rho(s)$ is:

$$
\rho(s)=s^{2}+\frac{f_{c}+k_{p \omega} P}{J} \cdot s+\frac{k_{i \omega} P}{J}=0
$$

By imposing two complex poles conjugated $s_{1,2}=\rho_{\omega} \cdot(1 \mp j)$ in closed loop and by identification, one obtains the parameters of the controller PI:

$$
\left\{\begin{array}{l}
k_{p \omega}=\frac{2 \cdot \rho_{\omega} \cdot J-f_{c}}{P} \\
k_{i \omega}=\frac{2 \cdot \rho_{\omega \cdot J}^{2} \cdot}{P}
\end{array}\right.
$$

\subsection{NLPI Controller}

For the control of the MAS by NLPI, we adopt the same device illustrated by Figure 1, except change of the CPI controller by another NLPI. In addition, we also use NLPI regulators for current regulation of the IFOC command.

At speeds reaching higher and higher thresholds, in an industrial environment where the transient mode is characterized by a strong non-linearity, it is even more judicious to call on the NLPI controller, in order to improve the quality of control even more. By guaranteeing impeccable speed control, we say that NLPI control is considered one of the most efficient and simple methods for industrial applications [10], [11], [14]-[17]. This control can be expressed for any control structure of the following form:

$$
u(t)=k_{p}(.) e(t)+k_{i}(.) \int e(\tau) d \tau
$$

Where are control gains $k_{p}($.$) et k_{i}($.$) varying over time, depending on the state of the system, the$ signal of the command and $\mathrm{e}(\mathrm{t})$ the error.

The action of the NLPI controller represented by the Figure 3:

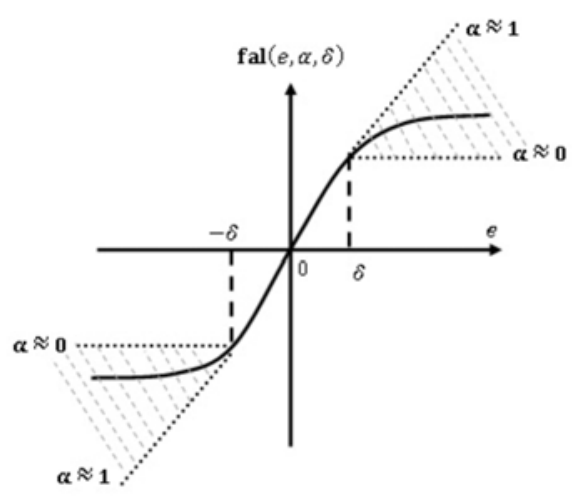

Figure 3. $f a l(e, \alpha, \delta)$ function characteristics

This control action is given by:

$$
u=k_{p} f a l\left(e, \alpha_{p}, \delta_{p}\right)+k_{i} f a l\left(\int e d t, \alpha_{i} \delta_{i}\right)
$$

With:

$$
f a l(e, \alpha, \delta)=\left\{\begin{array}{l}
|e|^{\alpha} \operatorname{sign}(e) \quad|e|>\delta, \delta>0 \\
\frac{e}{\delta^{1-\alpha}} \quad|e| \leq \delta
\end{array}\right.
$$




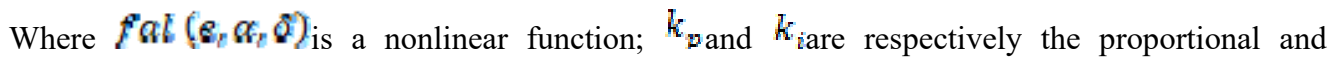
integral gains of the NLPI controller; $u_{i s}$ the command signal; the parameters $\alpha_{v a n d} \alpha_{\text {iare constant, }}$

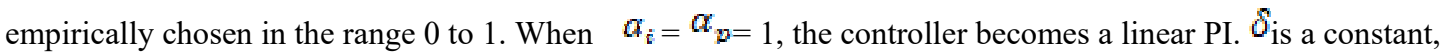
which can be empirically fixed to a small value.

The NLPI is thus designed by adapting its response based on the performance of the closed-loop control system. When the error between the controlled and actual values of the controlled variable is large, the gain amplifies the error substantially to generate a large correction to quickly drive the system out of its way. On the other hand, when the error decreases, the gain is reduced automatically to avoid excessive oscillations and large overshoots in the response. Thanks to this automatic gain adjustment, the NLPI controller has both a high initial gain and a fast response, followed by a small gain to avoid oscillatory behavior [17-25].

\section{SIMULATION RESULTS AND ANALYSIS}

A simulation series is performed for each of the two control cases described above, followed each time by a summary of the results and an in-depth analysis. All simulations take into account the dynamics of the torque, flux and current in the MAS subjected to the IFOC command.

To evaluate the tuning performance, we simulated each control case with speed controller parameters calculated by a pole location $\rho_{\omega}$, a set speed $\omega_{r}=150 \mathrm{rad} / \mathrm{s}$, followed by an application and a charge removal $\left(C_{c h}^{n}=10 \mathrm{~N} . \mathrm{m}\right)$ at times $t=1.5 \mathrm{~s}$ and $t=2.5 \mathrm{~s}$, respectively. Then an application of a set point change at the moment $t=4 s$.

Table 1 below shows the control parameters for each case:

Table 1. Parameters of control

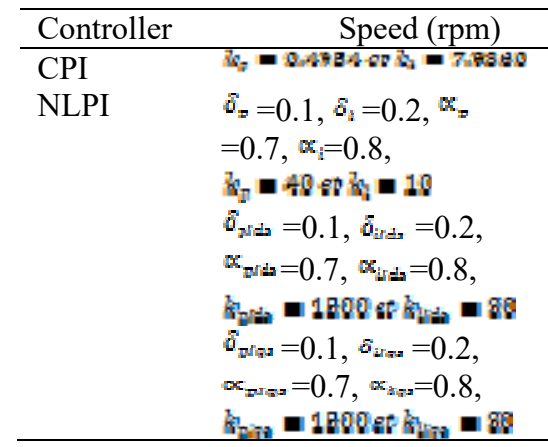

\subsection{Behavior of speed}

The analysis of Figure 4 shows Behavior of the output speed y with respect to that of the input $\omega_{s}$ (CPI case), allows us to deduce:

1. Registration of a transitional regime at start-up during $0,35 s$;

2. During this phase the speed follows its reference value with an overrun of $10 \mathrm{rad} / \mathrm{s}(y=$ $154 \mathrm{rad} / \mathrm{s}$ et $\omega_{r}=144 \mathrm{rad} / \mathrm{s}$ ) and this to $t=0.13 \mathrm{~s}$;

3. At the application of a load, at approximately $t=1.5 \mathrm{~s}$, we record a downward peak of a value of $y=142 \mathrm{rad} / \mathrm{s}$;

4. When lifting the load $(t=2,5 s)$, this time we record a peak at the top of a value $y=$ $158 \mathrm{rad} / \mathrm{s}$.

5. We then say that the speed decreases with the increase of the load and then increases with its decrease.

6. At $t=4 s$, the direction of rotation of the MAS changes. 


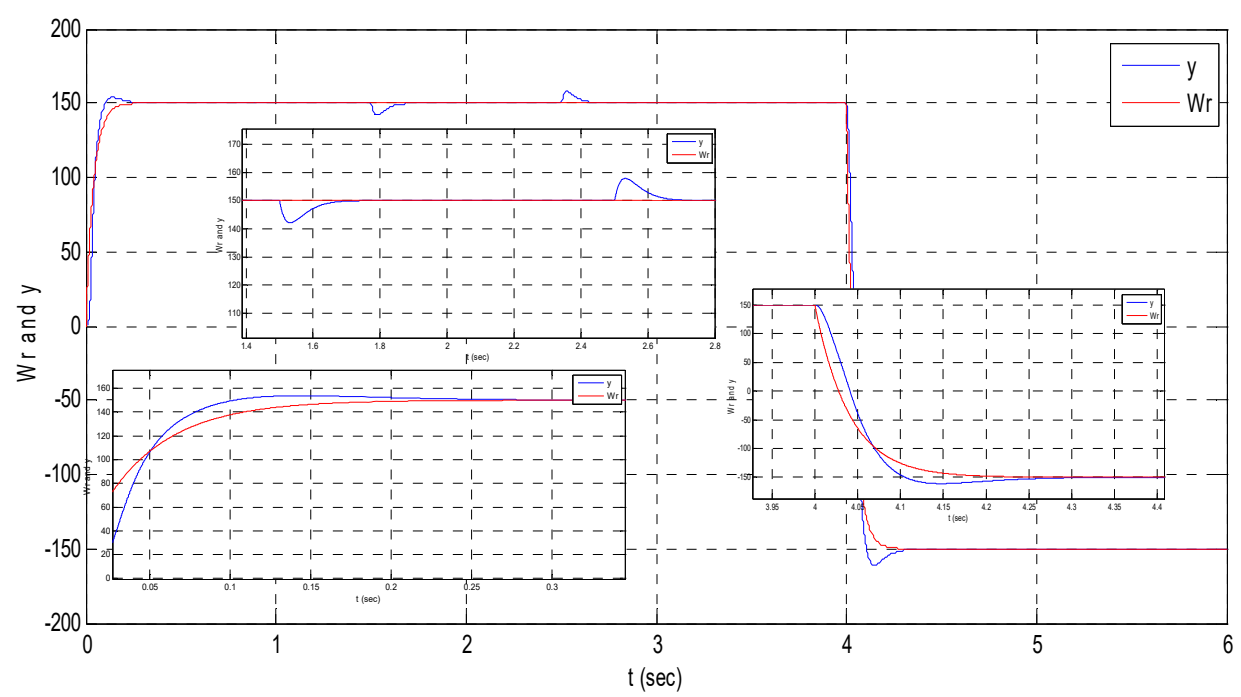

Figure 4. Behavior of the output speed y with respect to that of the input $\omega_{*}$ (CPI case)

Overall, therefore, we record a good reference tracking by that of the output and a good rejection of disturbances during the application of the load.

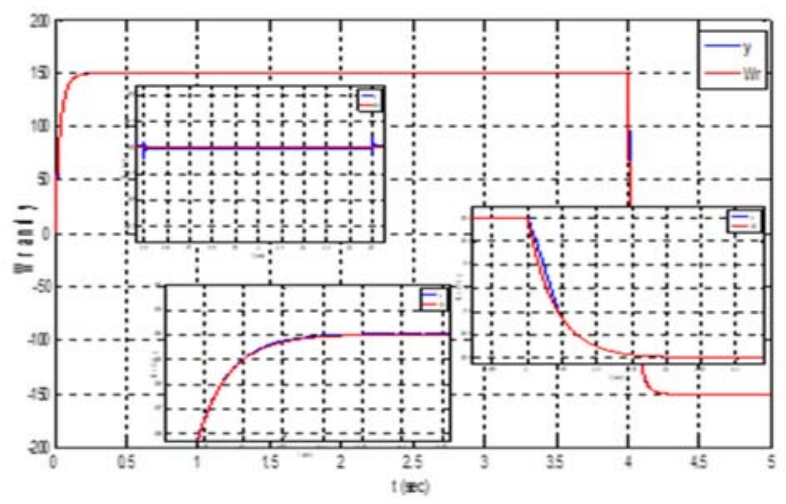

Figure 5. Behavior of the output speed y with respect to that of the input $w_{s}$ (NLPI case)

The analysis of Figure 5, allows us to deduce:

1. Registration of a transitional regime at start-up during $0,33 \mathrm{~s}$;

2. During this phase the speed follows its reference value with an overrun of $5 \mathrm{rad} / \mathrm{s}(y=$ $154 \mathrm{rad} / \mathrm{s}$ et $\omega_{r}=149 \mathrm{rad} / \mathrm{s}$ ) and this to $t=0.13 \mathrm{~s}$;

3. At the application of a load, at approximately $t=1.5 \mathrm{~s}$, we record a downward peak of a value of $y=149,7 \mathrm{rad} / \mathrm{s}$;

4. When lifting the load $(t=2,5 s)$, this time we record a peak at the top a value $y=$ $150,2 \mathrm{rad} / \mathrm{s}$.

5. We then say that the speed decreases with the increase of the load and then increases with its decrease.

6. At $t=4 s$, the direction of rotation of the MAS changes.

Overall, therefore, this time we record a better reference tracking by that of the output and a better rejection of disturbances during the application of the load and this compared to the control case at CPI. 


\subsection{Behavior of current}

Figure 6 shows current behavior $I_{d s}$ and $I_{q s}$ (CPI case).

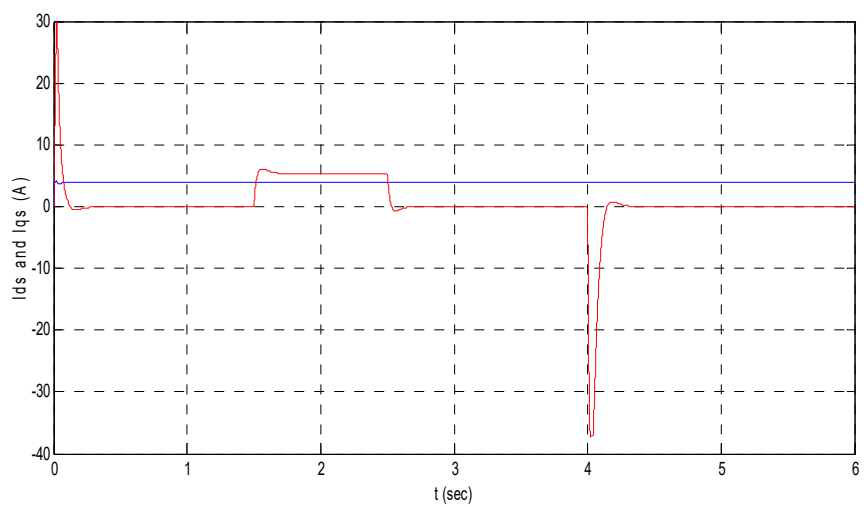

Figure 6. Current behavior $I_{d s}$ and $I_{q s}(\mathrm{CPI}$ case)

From the analysis figure 6 we can deduce:

a) Current $\boldsymbol{I}_{\boldsymbol{d} \boldsymbol{s}}$ :

In general, during the entire period between 0 and $4 \mathrm{~s}$, the current $I_{d s}$ stabilizes at about $3.9 \mathrm{~A}$.

b) Current $\boldsymbol{I}_{\boldsymbol{q} \boldsymbol{s}}$ :

i. The rise time between 0 to $0.13 \mathrm{~s}$ has a peak of about $30 \mathrm{~A}$.

ii. Throughout the interval from $t=1.5 \mathrm{~s}$ to $t=2.5 \mathrm{~s}$ a rise (with bumps at the ends) of about $6 \mathrm{~A}$.

iii. At $t=4 \mathrm{~s}$ a signal fluctuation indicates the change in the rotation of the MAS.

Figure 7 shows current behavior $I_{d s}$ and $I_{q s}$ (NLPI case)

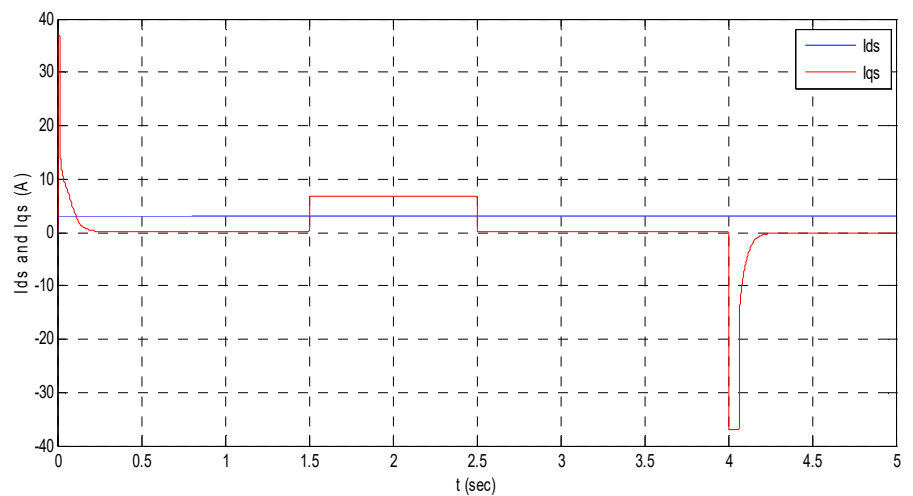

Figure 7. Current behavior $I_{d s}$ and $I_{q s}$ (NLPI case)

From the analysis figure 6 we can deduce:

a) Current $I_{d s}$ :

In general, during the entire period between 0 and $4 \mathrm{~s}$, the current $\boldsymbol{I}_{\boldsymbol{d} \boldsymbol{s}}$ stabilizes at about $3.1 \mathrm{~A}$.

b) Current $I_{q s}$ :

i. $\quad$ The rise time between 0 to $0.13 \mathrm{~s}$ records a peak of about $38 \mathrm{~A}$.

ii. Throughout the interval from $t=1.5 \mathrm{~s}$ to $\mathrm{t}=2.5 \mathrm{~s}$ a virtually rectangular rise (without end fluctuations) of about $6 \mathrm{~A}$.

iii. At $\mathrm{t}=4 \mathrm{~s}$ a signal fluctuation indicates the change in the rotation of the MAS. 


\subsection{Flux behavior}

Figure 8 shows flux behavior $\emptyset_{d r}$ and $\emptyset_{q r}$ (CPI case).

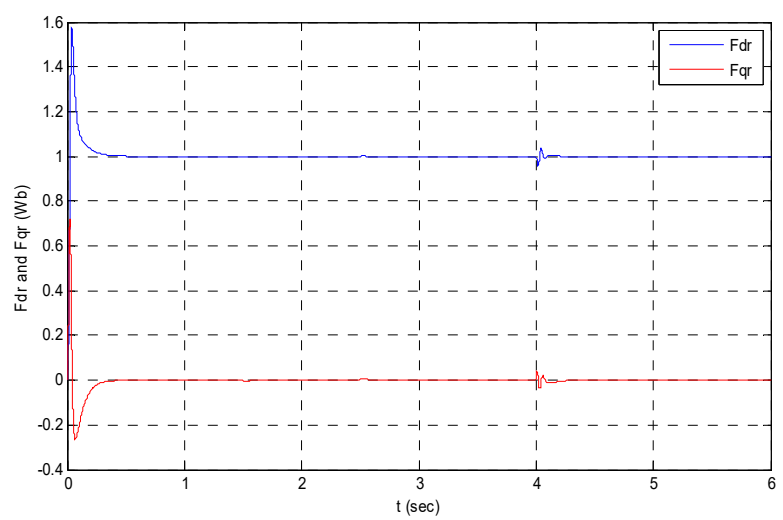

Figure 8. Flux behavior $\emptyset_{d r}$ and $\emptyset_{q r}$ (CPI case)

Figure 8 shows that the fluxes and consequently the electromagnetic torque are maintained at their desired values. Obviously, we record:

i. After a short transient departure, the two flows have fluctuations (ripples) at startup:

1. $\emptyset_{d r}=\left\{\begin{array}{l}1.6 \mathrm{~Wb} \text { (Alternance positive) } \\ 0 \mathrm{~Wb} \text { (Alternance négative) }\end{array}\right.$

2. $\emptyset_{q r}=\left\{\begin{array}{l}0.7 \mathrm{~Wb}(\text { Alternance positive }) \\ -0.3 \mathrm{~Wb} \text { (Alternance négative })\end{array}\right.$

ii. Very slight fluctuations at the moment of the lifting of the load at $t=2.5 \mathrm{~s}$;

iii. Slight fluctuations at the time of change of MAS rotation at $t=4 \mathrm{~s}$;

iv. During all the time, we can confirm the flow of the rotor knows only the reference flow $\left(\emptyset_{d r}=1\right.$ and $\left.\emptyset_{q r}=0\right)$ and is therefore independent of speed and torque variations. This implies a good decoupling.

Figure 9 shows Flux behavior $\emptyset_{\mathrm{dr}}$ and $\emptyset_{\mathrm{qr}}$ (NLPI case).

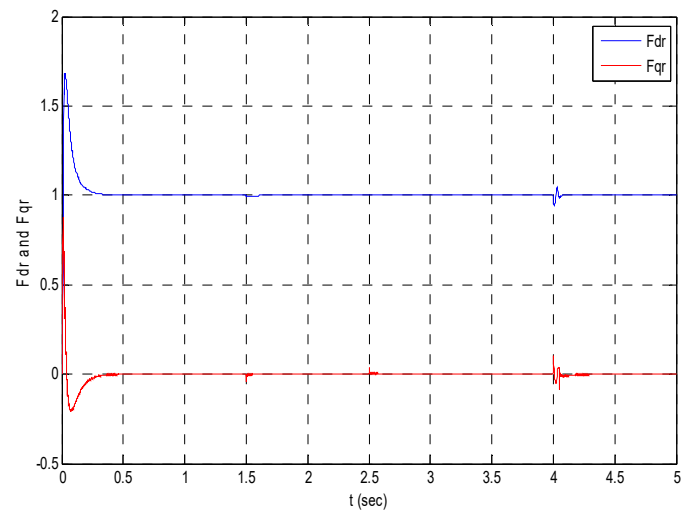

Figure 9. Flux behavior $\emptyset_{\mathrm{dr}}$ and $\emptyset_{\mathrm{qr}}$ (NLPI case)

Figure 9 shows that the fluxes and consequently the electromagnetic torque are maintained at their desired values. Obviously, we record:

i. After a short transient departure, the two flows have fluctuations (ripples) at startup: 
1. $\emptyset_{d r}=\left\{\begin{array}{l}1.7 \mathrm{~Wb}(\text { Alternance positive }) \\ 0 \mathrm{~Wb}(\text { Alternance négative })\end{array}\right.$

2. $\emptyset_{d r}=\left\{\begin{array}{l}1.7 \mathrm{~Wb} \text { (Alternance positive) } \\ 0 \mathrm{~Wb} \text { (Alternance négative) }\end{array}\right.$

ii. Slight fluctuations at the time of change of MAS rotation at $\mathrm{t}=4 \mathrm{~s}$;

iii. During all the time, we can confirm the flow of the rotor knows only the reference flow $\left(\emptyset_{d r}=1\right.$ and $\left.\emptyset_{q r}=0\right)$ and is therefore independent of speed and torque variations.

This implies a significantly improved decoupling compared to that of the CPI case.

\section{CONCLUSION}

Obviously, the constant development of research based on reflective and creative thinking for the continuous improvement of a speed controller putting an end to the constraints of the transient mode, led us to the NLPI. a controller thus ensuring a very good monitoring and an excellent rejection of disturbance is indeed the most effective way to ensure a better-quality treatment. The results of the simulations relating to a MAS commanded by IFOC and controlled by an NLPI controller are significantly improved, compared to the other ones of the CPI controller, that it is in terms of monitoring the speed of reference $\omega_{r}$ by that of the output $\mathrm{y}$, the rejection of disturbance or even behavior of the currents $I_{d s}$ and $I_{q s}$ and flux behavior $\emptyset_{d r}$ and $\emptyset_{q r}$ involving decoupling improvement. We will end by saying that the main importance of NLPI controllers lies in their robustness and performance against variations.

\section{ACKNOWLEDGEMENTS}

The authors wish to thank the anonymous reviewers for their suggestions and comments.

As well as the Director and the members of the CAOSEE laboratory of the department of electrical engineering of the Faculty of Technology of the university TAHRI MOHAMMED of Bechar and this for the assistance provided mainly in logistics.

\section{REFERENCES}

[1] O. Boughazi, A. Boumedienne, and H. Glaoui "Sliding Mode Backstepping Control of Induction Motor", International Journal of Power Electronics and Drive System (IJPEDS), Vol. 4, No. 4, pp. 481 488, 2014.

[2] A. Alalei, et al., "Self-Tuning Fuzzy Based PI Controller for DFIM Powered by Two Matrix Converters," International Journal of Power Electronics and Drive System (IJPEDS), vol/issue: 7(3), pp 665-676, 2016.

[3] N. Petit, P. Rouchon, "Automatic Dynamics and Systems Control", MINES ParisTech, CAS - Automation and Systems Center, Mathematics and Systems Unit, February 2011.

[4] P. Borne, G. dauphin, J-P. Richard, F. Rotella, "Contribution à la commande prédictive non linéaire d'une machine synchrone à aimants permanents", Thèse soutenue à Université UQAC CANADA, en 2010.

[5] N. Bezzouh "Commande Robuste du Moteur Asynchrone Basée Sur la Théorie de Lyapunov,"Thèse de Magister en Electrotechnique, Université HADJ LAKHDAR Batna, Algérie, 2010.

[6] A. Hazzab "Commande des systèmes par logique floue, réseaux neurones et algorithmes génétiques". Thèse de Doctorat ES Sciences, Université UST Oran, Algérie, 2006.

[7] T. Lameche. "Commande Robuste du Moteur Asynchrone Basée Sur la Théorie de Lyapunov," Thèse soutenu le : 06/05 /2010, HADJ LAKHDAR Batna, Algérie.

[8] S. De Hillerin, "Commande robuste de systèmes non linéaires incertains, " Edition HAL, archives-ouvertes.fr, 2013.

[9] Bousmaha Bouchiba, Abdeldjebar Hazzab, Hachemi Glaoui, Fellah Med-Karim, Ismaïl Khalil Bousserhane, Pierre Sicard, "Decentralized PI Controller for Multimotors Web Winding System", Journal of Automation, Mobile Robotics \& Intelligent Systems, 2012.

[10] A. Miloudi, "Etude et conception de régulateurs robustes dans différentes stratégies de commandes d'un moteur asynchrone," PhD Thesis, Universtity of Mohamed Boudiaf of Oran, Algeria, 2006.

[11] V. D. Yurkevic, "Advances in PID control”, Edition Published online 2011.

[12] T. M. Chikouche, A. Mezouar, T. Terras and S. Hadjeri. "Variable Gain PI Controller Design for Speed Control of a Doubly Fed Induction Motor", ETASR - Engineering, Technology \& Applied Science Research, Vol. 3, No. 3, 433-439, 2013.

[13] S. Boyd, M. Hast, and K. J. Åström, "MIMO PID tuning via iterated LMI restriction”, Int. J. Robust Nonlinear Control, vol 26, pp. 1718-1731, 2016.

[14] A. Omari, et al., "dSPACE DS1104 Based Real Time Implementation of Sliding Mode Control of Induction Motor," International Journal of Power Electronics and Drive System (IJPEDS), vol. 9, issue 2, pp. 546-558 2018.

[15] G. Imane, et al., "Neural Adaptive Kalman Filter for Sensorless Vector Control of Induction Motor," International Journal of Power Electronics and Drive System (IJPEDS), vol 8, issue 4, pp. 1841-1851, 2017.

[16] Shahruz SM, Schwartz AL. "Nonlinear PI compensators that achieve high performance," J Dyn Syst, Measure Control; vol. 119, no 5, pp. 105-10, 1997. 
[17] F. Mokhtari, P. Sicard and A. Hazzab. "Decentralized Nonlinear Control Strategies for Disturbance Rejection in Winding Systems". IEEE International Electric Machines \& Drives Conference (IEMDC), 2011.

[18] Y.X. Su a. b, Dong Sun a, B.Y. Duan b. "Design of an enhanced nonlinear PID controller". ELSEVIER, Mechatronics, vol 15, pp. 1005-1024, 2005.

[19] P.R. Pagilla, N.B. Siraskar, and R.V. Dwivedula, "Decentralized control of web processing lines," IEEE Transaction on control systems technology, vol. 15, No. 1, pp. 106-117, Jan. 2007.

[20] Y.X. Su, B.Y. Duan and C.H. Zheng, "Nonlinear PID control of a six-DOF parallel manipulator", IEE Proceedings online, china, 2004.

[21] P. Mishra, V. Kumar, K.P.S. Rana, "An on line tuned novel nonlinear PI controller for stiction compensation in pneumatic control valves", 2015 ISA. Published by Elsevier Ltd, 2015.

[22] J. Han, "Nonlinear Design Methods for Control Systems", The Proc. Of The 14th IFAC World Congress, Beijing, 1999.

[23] S. Takashi, Y. Negishi and B. Yasushi, "a TDOF PID control system design by referring to the md-pid control system and its sensitivities", 2013 European Control Conference (ECC), July 17-19, 2013, Zürich, Switzerland.

[24] K. J. Hunt, R. R. Maurer, "Comparison of linear and nonlinear feedback control of heart rate for treadmill running", ISSN: (Print) 2164-2583 (Online) Journal homepage: http://www.tandfonline.com/loi/tssc20, Zurich, 26 May 2016.

[25] Moteurs et Contrôleurs, Edition, Festo Eurl, E-mail : info_fr@,festo.com, 2017.

\section{BIOGRAPHIES OF AUTHORS}

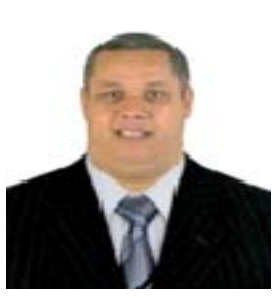

Mohammed TOUHAMI was born in Béchar (Algeria) on November 13, 1965. He graduated in engineering from DJILALI Liabès University, Faculty of Technology, Department of Electronics Engineering in Sidi Bel-Abbes (Algeria), in 1990. He received the Master of Electrical Engineering from TAHRI Mohammed University, Faculty of Technology, Department of Electrical Engineering in Béchar (Algeria), in 2013. Currently doing research at the laboratory CAOSEE University M. TAHRI Béchar to obtain a doctorate. His research interests concern: automation and industrial computing.

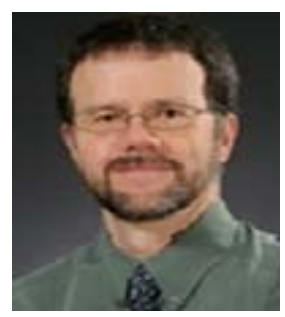

Pierre Sicard (S'84-M'85) received the B.S. degree in technology of electricity from the Superior Technology School, Montréal, QC, Canada, in 1985, the M.S. degree in industrial electronics from the University of Quebec at Trois Rivières, Canada, in 1990, and the Ph.D. degree in electrical engineering from Rensselaer Polytechnic Institute, Troy, NY, in 1993. He joined the University of Québec at Trois-Rivières as a Professor in electrical engineering, in 1992. He is currently Chairman of the Chaire de recherche Hydro-Québec sur la Puissance et l'Énergie Électrique (CPEE) and a member of the Research Group in Industrial Electronics, both at the Université du Québec at Trois-Rivières. His research interests concern: modeling, controller and observer design for nonlinear systems, control in power electronics, passivitybased control, adaptive control, and neural networks.

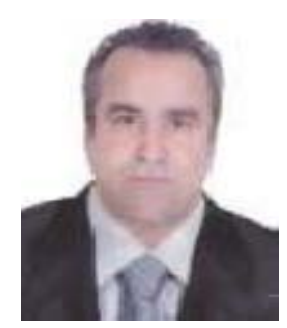

Abdeljebar Hazzab received his State Engineer, M.S., and Ph. D degrees in Electrical Engineering from the Electrical Engineering Institute of The University of Sciences and Technology of Oran (USTO), Algeria in 1995, 1999, and 2006, respectively. He is currently a Professor of Electrical Engineering at the University of Béchar (Algeria), where he has been the Director of the Research Laboratory of Command, Analyses, and Optimization of ElectroEnergetic Systems since 2009. His research interests concern: power quality, modeling, modern controller and observer design for nonlinear systems, control of power electronics, multidrive systems and electrical vehicle, and adaptive control and nonlinear systems diagnostic.

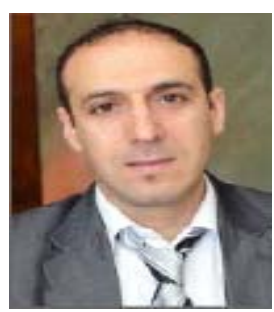

Mokhtari Fouad received his $\mathrm{PhD}$ degree in Electrical Engineering entitled "Controlling Hamiltonian Controlled Ports Systems. Application to a winder" from the University of Quebec at Trois-Rivières (CANADA) in 2010. He is Professor at the University of Technology, of Quebec at Trois-Rivières (CANADA). His research interests concern: industrial electronics, analogic and modeling, controller and observer design for nonlinear systems. 